\title{
Factors Affecting the Adoption of Water Harvesting Technologies: A Case Study of Jordanian Arid Area
}

\author{
Samia Akroush ${ }^{1}$, Boubaker Dehehibi ${ }^{2}$, Bezaiet Dessalegn ${ }^{3}$, Omamah Al-Hadidi ${ }^{1} \&$ Malek Abo-Roman ${ }^{1}$ \\ ${ }^{1}$ Socioeconomic Studies Directorate, National Center for Agricultural Research and Extension (NCARE), Baq'a \\ (19381). Amman, Jordan \\ ${ }^{2}$ Sustainable Intensification and Resilient Production Systems Program (SIRPSP), International Center for \\ Agricultural Research in the Dry Areas (ICARDA), Amman, Jordan \\ 3Integrated Water and Land Management Program (IWLMP), International Center for Agricultural Research in \\ the Dry Areas (ICARDA), Amman, Jordan \\ Correspondence: Samia Akroush, Socioeconomic Studies Directorate, National Center for Agricultural Research \\ and Extension (NCARE), Baq'a (19381).Amman, Jordan. E-mail: samia_akroush@yahoo.com
}

\author{
Received: August 16, 2016 Accepted: November 4, 2016 Online Published: December 16, 2016 \\ doi:10.5539/sar.v6n1p80 \\ URL: http://dx.doi.org/10.5539/sar.v6n1p80
}

\begin{abstract}
In this article, we investigate the determinants of farmers' decisions to adopt water harvesting technologies (WHT) in the arid agricultural area of Jordan. In particular, we investigate the effect of different socio-demographic, economic, and institutional factors on the adoption of WHT. For doing so, we empirically apply a binary logistic regression model on a micro-dataset (59 farmers) in Jordanian Badia. Empirical findings indicate that there is no significant relationship between age and the probability of adoption of WHT. However, our findings show significantly positive relationships at $10 \%$ level for farmer education and experience which implies that farmers with higher education and experience level are more likely to adopt WHT. In contrast, it was found that labor and institutional variables such as credit services do not significantly influence adoption of WHT. Results also reveal a significant relationship between land tenure and adoption implying higher adoption rates on communal land as opposed to privately owned land. Based on our empirical results, this research will assist decision makers to prioritize the factors influencing adoption of WHT and provide insights for targeted dissemination, adoption, and diffusion of WHT in the Jordanian arid areas.
\end{abstract}

Keywords: adoption decisions, water harvesting technologies, arid areas, logit, Jordan

\section{Introduction}

Water is the primary constraint to agricultural livelihoods in the drylands. Based on prediction of climate change in the region, farmers will be faced with continued and increased water scarcity and rising temperature which will negatively affect agricultural production (Olarinde et al., 2012). Improvement in agricultural water management is thus crucial to sustain current patterns of agricultural production and development over the coming decades (Verner and Breisinger, 2012; IBRD, 2007).

The Water and Livelihood Initiative (WLI) is a regional undertaking (Note 1) that aims to improve the livelihoods of rural households and communities in the MENA region, particularly in semi-arid and arid agricultural areas where water scarcity, land degradation, food security, and water quality deterioration are widespread. Its main objective is to develop and pilot test integrated water, land-use and livelihoods strategies in selected benchmark sites for scaling-out to agro-ecologically and socio-economically suitable areas in the region.

This study was undertaken within the framework of the WLI, to assess factors affecting adoption of the technologies developed and/or improved through the Initiative, with special emphasis on the identification of the constraints to and opportunities for adoption of selected WHT.

Previous research on adoption of water and land conservation technologies provide several insights into the relationship between farmers' demographic status and their decision to adopt or not adopt water and land conservation technologies. For instance, Teshome et al., (2015) examined the drivers of different stages on the adoption of soil and water conservation (SWC) technologies in the north-western highlands of Ethiopia. Their study was based on a detailed farm survey among 298 households in three watersheds. A simple descriptive 
statistics and an ordered probit model were used to analyze the drivers of different stages of adoption of SWC. The results of the ordered probit model show that some socio-economic and institutional factors affect the three adoption stages of SWC differently. Farm labor, parcel size, ownership of tools, training in SWC, presence of SWC program, social capital (e.g., cooperation with adjacent farm owners), labor sharing scheme, and perception of erosion problem have a significant positive influence on the actual and final adoption phases of SWC. Additionally, the final adoption phase of SWC was positively associated with tenure security, cultivated land sizes, parcels slopes, and perception on SWC profitability. The study recommended that policy makers should take into consideration factors affecting adoption of SWC such as profitability, tenure security, social capital, technical support, and resource endowments (e.g., tools and labor) when designing and implementing SWC policies and development programs.

Ahmed et al., (2013) evaluated the factors influencing adoption of rainwater harvesting technologies among households in Yatta district (Kenya). A semi-structured questionnaire was used to gather data from 60 households. Logistic regression was applied to evaluate different factors influencing adoption determinants of rainwater harvesting technologies. Findings from this study indicates that most of the farmers were aware of a variety of WHT, with roof WH (45\%) and dams (36.1\%) being rated high, and were willing to adopt them within their local context. The empirical regression findings showed that factors such as education level of household head, experience of water shortage, and awareness of WHT and age of farmers were significantly positive influencing WHT adoption. The study concluded that for effective implementation and subsequent adoption of rainwater harvesting technologies, farmers would require technical know-how and skills, capital, raw material and organizational support. In addition, farmers need to be mobilized and trained on the use of rainwater harvesting technologies and sensitized on the potential socioeconomic benefits of adopting them.

This paper offers insight into the constraints and determinants that influence Jordanian farmers' decision on adoption of WHT, and presents policy makers with important considerations for designing effective policies that could stimulate and sustain adoption of these technologies in arid agricultural areas.

The remaining part of this paper is organized as follows: Section 2 presents background information about the project and the technologies tested. The objectives of the study, study area and the methodology used are presented is Section 3. Section 4 presents the results of the binary regression model, the results of the technology characteristics, and the criteria that farmers used to judge the technology. The last section summarizes the main concluding remarks and implications.

\section{Background and Research Objective}

The WLI in Jordan aims to pilot test strategies for sustainable land and water management in the Jordanian rangeland areas commonly referred to as the Badia, focusing on the adaptation of WHT to ensure efficient use of scarce and fragile resources; to restore and reverse degraded and drought-prone areas; and to expand income generation opportunities for improved livelihoods.

Different types of WHT have been tested and applied through the WLI including the Vallerani, Run-off strips, and Marabs. The Vallerani mechanized system is a special tractor-pulled plow that automatically constructs water-harvesting catchments and is ideally suited for large-scale reclamation work (ICARDA Caravan, 2006). The other category of WHT is the Run-off strips, where barley is planted in strips using a seed drill, with unplanted strips in between catchment areas. The catchment areas allows rainfall water to be harvested in the barley planted strips, which will maximize the availability of water for barley, and as a result, the barley crop will give reasonable straw and grain yield. Another type of WHT practiced at the project area are the Marabs. These are natural formations found in the Badia where water spreads naturally over a relatively wide, slightly shallow "stream" beds and thus allow the use of this area for agricultural production (e.g., barley cultivation for feeding livestock). Streams are temporary due to low rainfall and aridity, and may not, in fact, exist every year. A Marab is a WHT that is constructed at the lowest point of the watershed to collect and spread excess runoff water in order to maximize the size of cultivated land.

The aim of this study is twofold: Firstly, to assess farmer's perceptions of and exposure to WHT, and to determine the major factors influencing farmer's adoption decisions and their willingness to adopt these practices. To the best of our knowledge, this is the first paper that offers such insight in the case of Jordan. According to Anderson (1993), willingness to adopt refers to a farmer's motivation to adopt a new innovation, technology, and/or practice. Secondly, the paper aims to estimate the elasticity of adoption of factors that are significant in explaining farmers' decisions in the study area and draw conclusions that might help in developing policy and institutional interventions in order to enhance and accelerate the adoption process and widespread of such technologies. 
The study objectives are based on the following hypothesis:

(a) The adoption of the WHT is dependent upon the level of human capital such as age, education, training, membership in farmer's organization and perception of soil degradation;

(b) It is assumed that farmers with large land holdings are more likely to adopt WHT than farmers with smaller land holdings, and

(c) The readiness of farmers to adopt WHT is conditional upon the availability and accessibility of appropriate equipment (case of Vallerani).

\section{Methodological Framework}

\subsection{Study Area}

The WLI project was implemented in two communities (Majidyya \& Muharib) at the middle Badia of Jordan. Majidyya is a rural village $70 \mathrm{~km}$ south of Jordan's capital city of Amman (Fig 1). With a small population of 40 household heads and approximately 250 inhabitants, the Majidyya community members traditionally use their lands for grazing.

Land degradation in the area is mainly attributed to continuous grazing which affects biodiversity, vegetation composition, and availability of essential biomass to sustain livelihoods. As an adaptation strategy, farmers have switched to barley cultivation because barley is a government-subsidized crop (farmers receive barley with lower prices than the world prices), and because despite its small yield potential due to water scarcity, nonetheless both the seed and the stalk offer farmers a good source of fodder for their livestock.

Muharib is also a small agricultural village with 30 household heads and about 190 inhabitants. Like Majidyya, $M$ uharib agriculture area has been suffering from water shortages/scarcity and degradation of arable land. Unable to earn enough in their agricultural livelihoods, some families have left Muharib for other neighboring villages or cities such as Amman where private and public services and employment provide more prospects for a better life.

The study site (Figure1) was selected as an area that is representative of conditions throughout the Jordanian Badia, based on carefully selected criteria including the area layout, runoff, slope, soil, rainfall, and the community. On average, the area receives between 100 and $200 \mathrm{~mm}$ of rain per year, and has one of the highest rates of evapotranspiration in Jordan. The selected pilot testing area also suffers from crust formation which reduces water infiltration. The Jordanian Badia is severely degraded due to continuous over-grazing, cutting, and ploughing; population growth, water shortages and climate change effects (drought).

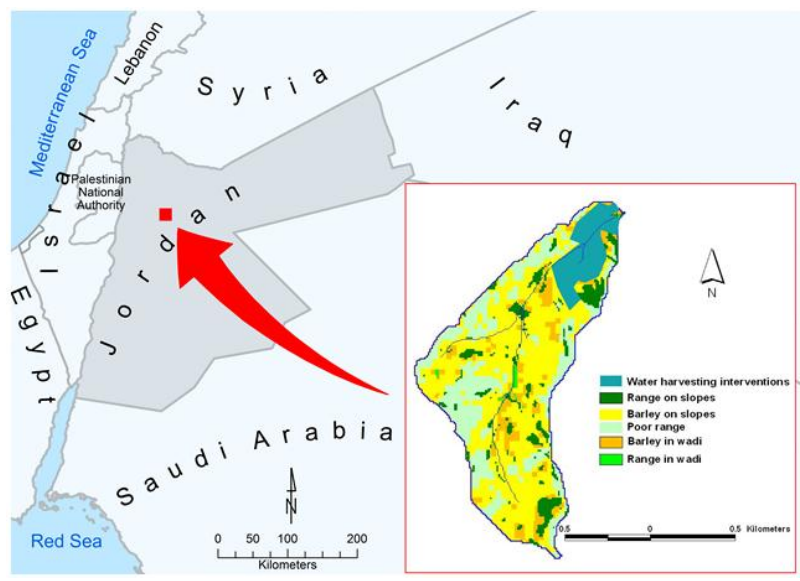

Figure 1. Location, land use and map of the study watershed in Jordan

Source: Akroush et al., (2014).

\subsection{Survey Design and Data Collection}

For the purpose of achieving the study objectives, sample of 59 farmers were selected using random sampling procedure. The survey was done on a sample of 25 adopters and 34 non-adopters of WHT. The distribution of the sample collected and sample size from the different locations is displayed in Table 1. Farmers were interviewed 
and survey was administered to the household heads for all selected households to gather the needed information.

Pre-testing of the questionnaire was done in the targeted communities to test its validity with farmer's conditions. Minor modifications were done through feedback from farmer's interviews and with participation of a multidisciplinary team. The information collected using the questionnaires covering several sections included information about farmers socio economic conditions, main crops planted and inputs used, animals owned, marketing livestock products, source of fodder/animal feed, water sources, access to credit, engagement in community based organizations, farmers' knowledge of the new technologies, basic criteria for technology adoption, WHT characteristics and challenges in current agricultural practices.

In addition to this questionnaire, and to facilitate the interpretation of the empirical findings, individual and collective informal discussions with farmers, farmers' associations and local institutions were organized. This was mainly to understand the local farming systems in this area with special emphasis on the WHT and WH management techniques in use by farmers.

Table 1. Distribution of sample by location

\begin{tabular}{llll}
\hline \multicolumn{2}{l}{ Farmers group/location } & No. of farmers & $\%$ \\
\hline \multirow{3}{*}{ Adopters } & Middle Badia (WLI site) & 13 & 52.0 \\
& Karak Governorate & 12 & 48.0 \\
Non-adopters & Total & 25 & 100.0 \\
\hline
\end{tabular}

Source: Own elaboration from survey database (2015).

This study used both qualitative and quantitative methods to analyze the gathered data. The data was collected, coded, entered and checked for consistency before proceeding with its statistical and empirical analysis using IBM SPSS statistics software (v.20). The gathered data was processed and analyzed to generate descriptive statistics (frequencies, mean, minimum, maximum, standard deviations, etc.) of factors expected to influence adoption of WHT and to describe farmers socio-economic characteristics, main crops planted, farmers assets, ownership of animals, marketing of livestock products, sources of fodder, water sources and the community's engagement in organizations in addition to farmer's knowledge to new technologies and finally the main challenges of farmers with respect to the current agricultural practices.

\subsection{Econometric Logit Model}

In the literature, the two most popular functional form used in adoption modeling are probit (which assumes an underlying normal distribution) and logit (which corresponds to a logarithmic distribution function). These models have got desirable statistical properties as the probabilities are bounded between 0 and 1 . Apparently, the choice of which continuous probability distribution to use cannot be justified on theoretical grounds (Amemiya, 1985). In this study, therefore the binary logistic regression is adopted.

A binary logistic regression is used to regress the dependent variable, Y, of weather the farmer had adopted WHT: $\operatorname{Prob}($ event $)=\operatorname{Prob}\left(\mathrm{Y}, 1\right.$ represents $\mathrm{i}^{\text {th }}$ farmer adopted, and 0 , otherwise $)$

$$
\mathrm{Y}=\left\{\begin{array}{c}
1: \text { adopted } \\
0: \text { otherwise }
\end{array}\right.
$$

Against the estimated factors affecting adoption of WHT, the below section describes the variable selection and hypothesis of these variables included in the logistic regression model.

\subsubsection{Variable Selection and Hypotheses}

The description of the following dependent and explanatory variables as well as the main hypotheses are given in Table 2. Table 3 shows the summary statistics of the variables used in the empirical model.

\subsubsection{Dependent Variable}

Given that our conceptual framework is based on the adoption process of WHT and on the concept of dis-adoption of the earlier adopted technologies, in the analytical framework adoption is defined in terms of a binary variable (adoption/no adoption). ADOP (referring to the dependent variable $\mathrm{Y}_{\mathrm{i}}$ ) is defined and categorized in this study as a binary variable with a value of 1 for those farmers who have adopted WHT and 0 for those who have not adopted it. The explanatory variables and hypotheses are discussed in the following section. 


\subsubsection{Explanatory Variables and Hypotheses}

The adoption of WHT is a complicated process similar to any other research on agricultural technology adoption (Adesina and Chianu, 2002) that may be influenced by a set of interrelated biophysical, social, economic, environmental and institutional factors. The seven potential explanatory variables (Table 2) expected to influence the adoption decision of WHT in the study areas include a wide variety of household socio economic, farming, and institutional factors.

\section{Review of major farmer variables and their expected effects}

$A G E$ : This variable measures the age of household head. According to the theory of human capital, young farmers are expected to have a greater chance of absorbing and applying new knowledge (Sidibe', 2005). Therefore, we hypothesized that successful use of WHT will be a challenge for older people i.e. older farmers will be less likely to adopt WHT than young people.

EDUC: Measures the level of education attained by a farmer. In most adoption studies (Ramji et al., 2002), farmers with higher levels of educational attainment are expected to adopt new technologies or practices than less educated farmers. Hence, it is expected that EDUC has a positive impact on adoption.

$\angle A B E$ : Refers to the size of the active-labor force. The unavailability of labor often limit farmers' use of WHT. Indeed, with the presence of a larger active-labor, a positive influence on the adoption of WHT is expected.

FEXP: Refers to farmers experience in farming. This consists of the knowledge and experience gained in farming. A positive influence on the adoption of WHT is expected with the presence of a larger experience in farming.

\section{Institutional and policy variables and their expected effects}

CRED: The accessibility of the households to cash credit (CRED) can help rural households in poor areas increase their production and consumption. Credit is expected to affect adoption of WHT positively. The CRED dummy variable would be expected to exert a positive influence on adoption of WHT.

\section{Farming variables and their expected effects}

TENUR: measures status of land ownership. There are three types of land tenure presented at the project site, owned, rented and shared lands. Land ownership, considered with a positive expected profit determinant, is widely believed to speed and encourage the adoption of new technologies but still it is difficult to forecast the sign of TENUR WH adoption.

Table 2. Variables used in the empirical Binary Logistic Model

\begin{tabular}{|c|c|c|c|}
\hline Acronym & Description & Type of measure & Expected Sign \\
\hline \multicolumn{4}{|c|}{ Dependent variable } \\
\hline ADOP & Whether a farmer has adopted or not & Dummy ( 1 if yes, 0 if no) & \\
\hline \multicolumn{4}{|c|}{ Explanatory variables } \\
\hline AGE & Household head's age & Years $(1,2,3,4)$ & - \\
\hline EDUC & $\begin{array}{l}\text { Educational background of } \\
\text { the household head }\end{array}$ & $1,2,3,4,5,6$ & + \\
\hline FEXP & Household head's farming experience & Years & + \\
\hline LABE & Labor force size & Active labor force numbers & + \\
\hline TENUR & Status of land ownership & 1 , fully owned; 2 , rented; 3 , shared & ? \\
\hline CRED & Obtained credit & Dummy ( 1 if yes, 0 if no) & + \\
\hline
\end{tabular}

Source: Own elaboration from survey database (2015).

\subsubsection{Modeling WH Harvesting Adoption Decision}

Binary logistic regression is a popular statistical technique in which the probability of a dichotomous outcome (such as adoption or non-adoption) is related to a set of explanatory variables (Table 3) and has been widely applied in adoption studies (Adesina and Chianu, 2002; Asfawa and Admassie, 2004; Chianu and Tsujii, 2004). In this development framework, farmers' adoption of WHT is based on an assumed basic utility function. According to this theory, WHT will be adopted by the farmer i, if the utility obtained from WHT exceeds that of non-adoption. The farmer's behavior towards WHT is described by Equations (1)-(4).

$$
\operatorname{Prob}(\text { event })=\operatorname{Prob}\left(\mathrm{Y}, 1 \text { represents } i^{\text {th }} \text { farmer adopted, and } 0 \text {, otherwise }\right)
$$


Let's define $X_{i}$ a vector representing the set of parameters including the factors which influence the adoption decisions of the $\mathrm{i}^{\text {th }}$ farmer on WHT. For the farmer $\mathrm{i}, \mathrm{Z}_{\mathrm{i}}$ is an indirect utility derived from the adoption decision, which is presented as a linear function of $\mathrm{K}$ explanatory variables $(\mathrm{X})$, and is expressed as:

$$
\mathrm{Z}_{\mathrm{i}}=\beta_{0}+\sum_{i=1}^{n} \beta i X k i
$$

where $\beta_{0}$ is the intercept term, and $\beta_{1}, \beta_{2}, \beta_{3}, \ldots$., $\beta_{\mathrm{i}}$ are the coefficients associated with each explanatory variable $\mathrm{X}_{1}, \mathrm{X}_{2}, \mathrm{X}_{3}, \ldots \ldots, \mathrm{X}_{\mathrm{ki}}$. Grouped in a vector $\mathrm{X}$, these factors explain the WHT adoption decision, or the probability that the $\mathrm{i}^{\text {th }}$ farmer adopts WHT:

$$
\mathrm{P}_{i}=\frac{e^{Z i}}{1+e^{Z i}}
$$

Where; $\mathrm{P}^{\mathrm{i}}$ denotes the probability that the $\mathrm{i}^{\text {th }}$ farmer's adoption decision and $\left(1-\mathrm{P}_{\mathrm{i}}\right)$ is the probability that $\mathrm{Y}_{\mathrm{i}}$ is 0 . The odds $(Y=1$ versus $Y=0)$ to be used can be defined as the ratio of the probability that a farmer adopts $\left(P_{i}\right)$ to the probability of non- adoption $\left(1-\mathrm{P}_{\mathrm{i}}\right)$, namely odds $=\mathrm{P}_{\mathrm{i}} /\left(1-\mathrm{P}_{\mathrm{i}}\right)$. By taking the natural log, we get the prediction equation for an individual farmer:

$$
\ln \left(\left(\frac{\mathrm{Pi}}{1-P i}\right)=\ln \text { odds }=\beta_{0}+\sum_{i=1}^{n} \beta i X k i=\mathrm{Z}_{\mathrm{i}}\right.
$$

Where $\mathrm{Z}_{\mathrm{i}}$ is also referred to as the $\log$ of the odds ratio in favor of adoption.

Table 3. Statistics of the variables used in the empirical logit model

\begin{tabular}{lcccc}
\hline Variable & Minimum & Maximum & Mean & Std. Deviation \\
\hline ADOP & 0 & 1 & 0.42 & 0.498 \\
AGE & 25 & 75 & 49.61 & 13.618 \\
EDUC & 1 & 5 & 3.10 & 1.213 \\
FEXP & 5 & 60 & 20.47 & 12.338 \\
LABE & 1 & 7 & 1.98 & 0.777 \\
TENUR & 1 & 6 & 1.69 & 1.290 \\
CRED & 0 & 1 & 0.32 & 0.471 \\
\hline
\end{tabular}

Source: Own elaboration from survey database (2015).

\section{Results and Discussion}

\subsection{Basic Criteria for WHT Adoption Decision}

Adoption and diffusion theory has been widely used to identify the factors that influence an individual's decision to adopt or reject an innovation. The perceived originality of the idea for the individual (farmer) determines his or her response to it. Rogers (1995: p11) identified five characteristics of an innovation that affect an individual's adoption decision:

Relative advantage: Is a determinant on the degree to which the innovation is perceived as better than the idea it supersedes. Relative advantage refers to the extent to which the innovation is more productive, efficient, costs less, or improves in some other manner upon existing practices.

Compatibility: Is the characteristic measuring the degree to which the innovation is perceived as being consistent with existing values, past experiences, and needs of potential adopters. An innovation must be considered socially acceptable to be implemented. And some innovations require much time and discussion before they become socially acceptable.

Complexity: Explain accurately how difficult the innovation is to understand and use.

Trialability: Indicates the degree to which the innovation may be experimented with on a limited basis. Innovations are easier to adopt if they can be tried out in part, on a temporary basis, or easily dispensed with after trial.

Observability: This is an indicator on the degree to which the results of the innovation are visible to others. The chances of adoption are greater if folks can easily observe relative advantages of the new technology. In fact, after some adopt, observability can improve the diffusion effect, a critical component of technology transfer.

A Likert scale of five, strongly agree (5) and strongly disagree (1) was used to assess the above mentioned characteristics of adopters of WHT at the WLI project site. This Likert scale is an ordered scale from which respondents choose one option that best aligns with their view. It was used to measure farmer's attitudes by 
asking the extent to which they agree or disagree with a particular question or statement on WHT characteristics. Results from this assessment are displayed in Table 5 and Figure 1.

The promising results indicates that farmers agreed to adopt WHT because it reduces risk in agriculture production (Coefficient 9.56), the technology is compatible (coefficient 9.48), is triable, easy to follow up and easy to implement (coefficient 9.33), and has environmental benefits (coefficient 9.4). However, the majority do not agree that this technology is affordable especially the Vallernai WHT (Coefficient 6.96), it needs skills and knowledge (coefficient 5.35), and is complex (coefficient 4.43). Please refer to Figure 2.

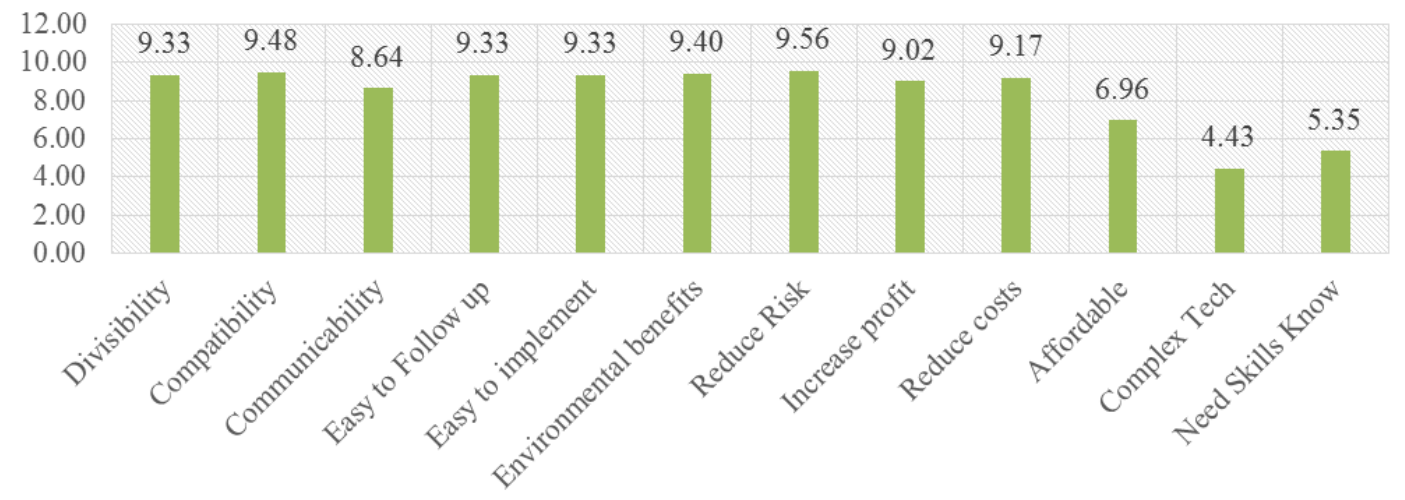

Figure 2. Criteria of WHT characteristics

Source: Own elaboration from survey database (2015).

\subsection{Regression Model-Binary Logistic Model (Logit)}

The following section presents the results of the binary logistic regression model. The validity of the model is initially discussed before presenting the empirical findings.

\subsubsection{Validity of the Model}

The maximum likelihood methods (MLE) was used to estimate the coefficients of the binary logistic regression model. The Hosmer and Lemeshow statistic is one of the most consistent goodness of fit test to assess if the model fits for the binary regression (Sidibe', 2005). The results of the model are given in Table 4. The overall percentage of correct predictions is about $69.5 \%$. The p-value 0.868 uses the Hosmer and Lemeshow Goodness-of-Fit Test, which is computed from the Chi-square distribution with 8 degrees of freedom (d.f), confirms the model's estimates very well fit the data. This implies that we fail to reject the null hypothesis that there is no difference between the observed and predicted values of the dependent variable. This implies that, at an acceptable level, the model's estimates are very consistent with the data. However, another strand of the econometric literature (Sidibe', 2005) argues that a p-value less than 0.05 indicate a poor fit for a binary logistic regression model.

The corresponding odds ratio ( Column, Exp ( $\beta$ )), in Table 5, gives the exponential of expected value of $\beta$ raised to the value of the logistic regression coefficient, which is the predicted change in odds for a unit increase in the corresponding explanatory variable.

Table 4 displayed that only two (2) explanatory variables in the model were statistically significant at the 5\% level in explaining WH adoption behavior in the Jordan Badia expressed in terms of the variables used in this case, and the logistic regression equation is:

$$
\ln \left(\left(\frac{\mathrm{Pi}}{1-P i}\right)=\ln \text { odds }=-2.44+0.015 \operatorname{AGE}(0,03)+0.457 \operatorname{EDU}(0,298)+0.067 \operatorname{FEXP}(0.036)+0.324\right.
$$

$$
\text { LABE(0.501)-1.67 TENURE(0.695)+0.567 CRED(0.719) }
$$

Information on the relationship between the explanatory variables and the dependent variable is provided in these estimates, where the dependent variable is on the Logit scale.

\subsubsection{Empirical Results of the Model and Discussion}

Farmers' resource endowment and socioeconomic characteristics

Results for the logistic model show that two characteristics (age and credit) of farmers are non-significant in the 
decision to adopt WHT and two characteristics (education and farm experience) are significant (Table 5). The empirical findings showed that there is no significant relationship between age and the probability of adoption of WHT so farmer age is not a determinant factor for adopting WHT. However, farmer education (EDU) has a positive impact in the adoption of WHT demonstrated by a significant relationship at 10\% level of significance.

We hypothesized that farmers with higher levels of education are more likely to adopt WHT. In line with our predictions, our results showed significant relationship between adopting WHT and higher educational level at $10 \%$ level of significance. As hypothesized, the farmer experience (FEXP) coefficient was also found to be significant and positively correlated with adoption decision at the $10 \%$ level of significance. The variable labor (LABE) was found to be non-significant in its relationship with adopters. This finding is consistent with our expectations which indicate that such technologies do not need much labor force especially the mechanized WHT.

Exp $(\beta)$ shows that holding all other explanatory variables constant, for every one unit increase in EDUC score, we expect a 1.58 times increase in the log-odds of adoption (the probability of adoption). There is a tendency for increasing adoption of WHT with increasing farmer's education level. The Exp ( $\beta$ ) also shows that holding all other explanatory variables constant, for every one -unit increase in FEXP score, we expect a 1.07 times increase in the log-odds of adoption (the probability of adoption). The same trend was found for increasing adoption of WHT with increasing farmer's experience in agriculture. The $\operatorname{Exp}(\beta)$ of land tenure showed also that holding all other explanatory variables constant, for every one-unit increase in TENURE score, we expect a 0.188 times decrease in the log-odds of adoption (the probability of adoption). Finally, the results show that there is a propensity for decreasing adoption of WHT with increasing farmer's private ownership of land. While this sounds contrary to adoption literature, the reason lies in the high investment costs associated with adoption of these technologies at a large-scale level. Farmers thus tend to adopt such large scale WHT interventions as a group.

\section{Institutions and policies factors}

The results of our study show that institutional variables such credit services (CRED) have no impact on the decision to adopt WHT. This implies that farmers do not use credit for the purpose of establishing WHT which is very high (the establishment cost of the technologies). We found a significant relationship between land tenure (TENUR) and adoption. This implies that adoption decreases when land is privately owned, and giving the fact that the upfront cost is too big, farmers are more interested to invest as a group or on communal lands and are more willing to share the cost of adoption. (Table 5).

Table 5. Parameter estimates of the binary logistic regression model for factors influencing adoption of WHT in Jordan Badia

\begin{tabular}{lccccc}
\hline Variable & $\beta$ & S.E. & Wald & Sig. & $\operatorname{Exp}(\beta)$ \\
\hline AGE & 0.015 & 0.030 & 0.254 & 0.615 & 1.015 \\
EDUC** & 0.457 & 0.298 & 2.358 & 0.125 & 1.580 \\
FEXP* & 0.067 & 0.036 & 3.448 & 0.063 & 1.070 \\
LABE & 0.324 & 0.501 & 0.420 & 0.517 & 1.383 \\
TENUR ** & -1.670 & 0.695 & 5.777 & 0.016 & 0.188 \\
CRED & 0.567 & 0.719 & 0.622 & 0.430 & 1.763 \\
Constant & -2.440 & 2.350 & 1.078 & 0.299 & 0.087 \\
\hline
\end{tabular}

Hosmer and Lemeshow Test: Chi-square, 3.881; df., 8; Sig., 0.868

-2 Log likelihood 57.613a ; Cox \& Snell R Square, .321; Nagelkerke R Square, .431

The overall percentage of correct predictions, $69.5 \%$.

*Significance at $5 \%$.

**Significance at $10 \%$.

*** Significance at $1 \%$.

Source: Own elaboration from model results (2015).

\section{Concluding Remarks}

The basic objective of the WLI in Jordan is to improve livelihoods of smallholder farmers in the Badia. This study was conducted to enhance our understanding of factors influencing adoption of proven WHTs in an effort to provide insights on pathways to increase the adoption of WHT in Jordanian Badia. 
Based on the results of the study, we recommend that institutions involved in the development and dissemination of WHT in the Jordanian Badia, take into consideration farmers' age, educational level, and availability of active labor force in their efforts to promote adoption of WHT. The study offers a different perspective to earlier efforts to promote the use of WHT which were based on purely technical dimensions such as agronomic and biophysical characteristics. The lessons from this study are that non-consideration of household socio demographic, economic and institutional characteristics may lead to inappropriate targeting of WHTs and would delay the dissemination and widespread of the technology at larger scale. Farmers at the study area facing many challenges related to applying WHT such as weather conditions, high prices of agricultural inputs in addition to high investment costs in using mechanized WH equipment. This emphasized that technologies should not be imposed, but should be driven by the willingness of farmers. Creating strong awareness amongst farmers' communities, relevant stakeholders and decision makers before trying to scaling-up this WH technology is crucial.

In arid areas, increasing farmers' knowledge and perception of the merits of WHT through better access to technical information, extension, and training is often cited as central to helping them on developing a positive assessment of WHT. This highlighted the need for policy support to encourage farmers to adopt this technology at their farms by providing loans with low interest rates targeted only for investment with such technologies, since the mechanized WH is costly and not affordable by farmers, and consequently accelerate the adoption process of these promising technologies. Therefore, any development intervention intended to enhance agricultural productivity through promoting WHT in the study area need to take into account the most important variables with respect to the type of innovation and farmers' preference.

Finally, along these lines, our research findings revealed the need for greater political and institutional input into WHT projects. In precise manner, there is a need to design and develop alternative effective policy instruments and mechanisms, strong institutional options for extension services, technical assistance, training and capacity building that will facilitate adoption the technology through participatory practices to ensure better fit to the needs of farmers. Creation of strong networking among different institutions related to applying WHT and involvement of civil societies, public and private financial institutions and support services could be an example of mechanisms to enhance WHT adoption in Jordan Badia. More specifically, linking mechanisms between research and extension and extension education on WHT would further push the adoption of such water management technologies at farm level. Yet, only technologies with a high financial feasibility should be promoted and therefore farmers should be encouraged to join established and strengthened associations through which training, technical assistance and help with access to extension information can be provided. This can only be achieved through planned and designed programs in partnerships with all concerned organizations and targeting the right beneficiaries.

\section{Acknowledgment}

The authors thank the Water Livelihood Initiative (WLI) initiative (http://wli.icarda.org/) led by ICARDA (http://www.icarda.org) and sponsored by the USAID (https://www.usaid.gov/) for funding this research.

\section{References}

Ahmed, I., Onwonga, R., Mburu, M., \& Elhadi, D. (2013). Evaluation of Types and Factors Influencing Adoption of Rainwater Harvesting Techniques in Yatta district, Kenya. International Journal of Education and Research Vol. 1 No. 6 June 2013Adesina, A.A., \& Chianu, J. (2002). Determinants of farmers' adoption and adaptation of alley farming technology in Nigeria. Agroforestry Systems, 55, 99-112.

Akroush, S., Shideed, K., \& Bruggeman, A. (2014). Economic analysis and environmental impacts of water harvesting techniques in the low rainfall areas of Jordan. International Journal of Agricultural Resources Governance and Ecology, 10(1), 34-49. https://doi.org/10.1504/IJARGE.2014.061040

Amemiya, T. (1985). Advanced Econometrics, Harvard Univ. Press.

Anderson, J. R. (1993). The economics of new technology adaptation and adoption. Revue of Marketing and Agricultural Economics, 61, 301-309.

Asfawa, A., \& Admassie, A. (2004). The role of education on the adoption of chemical fertiliser under different socioeconomic environments in Ethiopia. Agricultural Economics, 30, 215-228. https://doi.org/10.1111/j.1574-0862.2004.tb00190.x

Chianu, J. N., \& Tsujii, H. (2004). Determinants of farmers' decision to adopt or not adopt inorganic fertilizer in the savannas of northern Nigeria. Nutrient Cycling in Agroecosystems, 70, 293-301. https://doi.org/10.1007/s10705-004-0715-z 
ICARDA., (2006). The Vallerani Water Harvesting System, ICARDA Caravan No. 23, December 2006.

International Bank for Reconstruction and Development (IBRD) (2007). Making the most of scarcity : accountability for better water management results in the Middle East and North Africa. In MENA development report on water, ed. W. Bank, 270. Washington D.C.: World Bank.p. cm. https://doi.org/10.1596/978-0-8213-6925-8

Olarinde, L., Oduo, L., Binam, J., Diagne, A, Njuki, J., \& Adekunle, A. A. (2012). Impact of the Adoption of Soil and Water Conservation Practices on Crop Production: Baseline Evidence of the Sub Saharan Africa Challenge Programme. American-Eurasian Journal of Agricultural \& Environmental Sciences, 12(3), 293-305, 2012 ISSN 1818-6769 ( IDOSI Publications, 2012.

Ramji, P., Neupane, K. R., \& Sharma, G. B. T. (2002). Adoption of agroforesty in the hills of Nepal: a logistic regression analysis. Agricultural Systems, 72, 177-196. https://doi.org/10.1016/S0308-521X(01)00066-X

Rogers, E. M. (1995). Diffusion of innovations. Everett M. Rogers, $4^{\text {th }}$ ed.

Sidibe', M. (2005). Farm-level adoption of soil and water conservation techniques in northern Burkina Faso. Agricultural Water Management, 71, 211-224. https://doi.org/10.1016/j.agwat.2004.09.002

Teshome, A, Graaff., J., \& Kassie, M. (2015). Household-Level Determinants of Soil and Water Conservation Adoption Phases: Evidence from North-Western Ethiopian Highlands. Environmental Management, 57(3), 620-636. https://doi.org/10.1007/s00267-015-0635-5

Verner, D., \& Breisinger, C. (2012). Adaptation to a Changing Climate in the Arab Countries-A Case for Adaptation Governance and Leadership in Building Climate Resilience. 441. Washington D.C.: World Bank. https://doi.org/10.1596/978-0-8213-9459-5

\section{Copyrights}

Copyright for this article is retained by the author(s), with first publication rights granted to the journal.

This is an open-access article distributed under the terms and conditions of the Creative Commons Attribution license (http://creativecommons.org/licenses/by/3.0/). 